\title{
Our computational nature: comment on Barrett et al.
}

\author{
John Klasios* \\ York University, Toronto, ON, Canada \\ *Correspondence: john.klasios@gmail.com \\ Edited by: \\ J. Michael Williams, Drexel University, USA \\ Reviewed by: \\ Aaron T. Goetz, California State University, Fullerton, USA
}

Keywords: evolutionary psychology, computationalism, human nature, computers, cognitive science

\section{A commentary on}

From computers to cultivation: reconceptualizing evolutionary psychology

by Barrett, L., Pollet, T. V., and Stulp, G. (2014). Front. Psychol. 5:867. doi: 10.3389/fpsyg.2014.00867

I argue that Barrett et al. (2014) have misinterpreted evolutionary psychologists' notion of computation. Barrett et al. seemingly presume that the notion of computation deployed by evolutionary psychologists (e.g., Pinker, 1997; Tooby and Cosmides, 2005) is tantamount to positing a physical architecture whose form of computation proceeds via the syntactic-like transformations of spatially discrete representational symbols or sentence-like structures-i.e., in the manner of a Turing machine. But this is simply not the notion of computation that evolutionary psychologists advocate (in spite of the fact that a Turing machine architecture, for instance, is nonetheless compatible with it).

The notion of computation is philosophically complex, with many different meanings and a multifaceted history (Piccinini, 2012). By “computation," evolutionary psychologists fundamentally mean to say that the brain evolved to compute in the generic sense of the term. This more generic notion of computation, and its relation to a physical substrate, is outlined by Pinker (2005):

\footnotetext{
"Computation" ... does not refer to what a commercially available digital computer does but to a more generic notion of mechanical rationality .... In this conception, a computational system is one in which knowledge and
}

goals are represented as patterns in bits of matter ("representations"). (p. 2, emphasis added)

The misunderstanding of what evolutionary psychologists mean by computation also leads Barrett et al. to view various other conceptions of cognitioni.e., embodied, embedded, extended, enactive-as alternatives to the computational approach when, in actuality, they can easily be seen as complementary to it. For evolutionary psychologists are primarily focused on the functional level of analysis of psychological adaptations rather than their physical instantiations (i.e., their causal-physical basis in the brain, body, and wider environment). And this focus on the functional level of analysis allows researchers to investigate psychological adaptations in a manner that abstracts away from their instantiations in the brain, body, and larger context (i.e., ecological) in which they are embedded. The modular, computational framework of evolutionary psychology is quite compatible with, and can be meaningfully situated within, an overall physical and causal account that is highly complex, widely distributed, and highly diffuse. So, far from invalidating or highlighting a "prejudice" inherent to computationalism or evolutionary psychology, the supposed alternative approach that Barrett et al. advocate is rather a difference of focus and emphasis. For there is nothing within the theoretical approach of evolutionary psychology that in principle denies the existence of the kinds of "E-cognition" that Barrett et al. draw attention to. At a pragmatic level, different research programs will simply find it profitable to have differing explanatory focuses and emphases.

Barrett et al. also raise skepticism regarding the relationship between psychological adaptations and their neurobiological underpinnings. But it is important to note that the form-function fit that evolutionary psychologists focus on qua adaptationists pertains most directly to aspects of "psychological design" rather than to properties of the neurobiological realization of those designs. Thus, the reverse-engineering approach accordingly homes in on the psychological level of analysis and not the neurobiological one (or at least not primarily). More generally, at this stage of the game it is premature to draw overly strict conclusions on precisely how psychological adaptations may or may not be instantiated in the brain-e.g., if and how they are "multiply realizable" by neurobiological bases, and whether to interpret neuroimaging results according to a regionally-focused or network-wide perspective, etc. (e.g., Klein, 2012; Colombo, 2013).

Barrett and colleagues' discussion of human nature is also problematic. For instance, they endorse Wheeler and Clark's (2008) conception of human nature as "a kind of meta-nature ... an extended cognitive architecture whose constancy lies mainly in its continual openness to change" (p. 3572) and lead the reader to believe that it is necessarily at variance with the notion of human nature alluded to by evolutionary psychologists. On the contrary, however, evolutionary psychologists recognize this underlying constancy and refer to it as our underlying "developmental programs" (e.g., Tooby et al., 2003). For evolutionary psychologists, human nature is tantamount to the 
ontogenesis of our species-typical psychological adaptations. On this view, human nature is envisioned as being expressed through development in ways that are guided, generative, and constrained. The precise details of how guided, generative, and constrained this underlying nature is are of course a complex empirical matter that has barely just commenced, scientifically speaking. At any rate, abstractly modeling postulated psychological adaptations in computational terms is an invaluable method of investigation (see Barrett, 2006, 2007; Bechtel, 2007; Tooby and Cosmides, 2008; Frankenhuis et al., 2013; Levy and Bechtel, 2013).

Indeed, evolutionary psychologists argue that our developmental programs should be computationally mapped in ever-increasing detail, ultimately yielding a high-resolution map of human nature. Barrett et al. claim that human nature can be "cultivated," shaped, and refracted (etc.). But the extent to which this is possible is ultimately an empirical question, and the more we can understand the nature of our developmental programs, the less need we will have for such vague notions. And in any case, however much we can cultivate our developmental programs, they are fundamentally a product of past selection and thus cannot be adapted-in the adaptationist senseconditions (e.g., Tooby and Cosmides, 1990).

Barrett et al. also crucially omit certain aspects of evolutionary psychologists' treatment of culture. To wit, Barrett et al. imply that evolutionary psychologists cannot account for the way in which material artifacts, beliefs, and so forth, interact with the underlying developmental programs undergirding our species-typical cognitive architecture. To the contrary: evolutionary psychologists' notion of epidemiological culture refers both to the transmission of culture between individual minds and its impact on the cognitive architecture of those minds (Tooby and Cosmides, 1992;
Sperber, 1996). Furthermore, models of epidemiological culture can, in principle, be as complex and dynamic as need be. Hence, the allegations by Barrett et al. that evolutionary psychology is inconsistent with or fails in principle to account for such cultural phenomena are baseless.

\section{ACKNOWLEDGMENT}

Thanks to Aaron Goetz for the useful comments.

\section{REFERENCES}

Barrett, H. C. (2006). "Modularity and design reincarnation," in The Innate Mind: Volume 2: Culture and Cognition, eds P. Carruthers, S. Laurence, and S. Stich (New York, NY: Oxford University Press), 199-217.

Barrett, H. C. (2007). "Development as the target of evolution: a computational approach to developmental systems," in The Evolution of Mind: Fundamental Questions and Controversies, eds S. W. Gangestad and J. A. Simpson (New York, NY: The Guilford Press), 186-192.

Barrett, L., Pollet, T. V., and Stulp, G. (2014). From computers to cultivation: reconceptualizing evolutionary psychology. Front. Psychol. 5:867. doi: 10.3389/fpsyg.2014.00867

Bechtel, W. (2007). "Reducing psychology while maintaining its autonomy via mechanistic explanation," in The Matter of the Mind: Philosophical Essays on Psychology, Neuroscience and Reduction, eds M. Schouten and H. Looren de Jong (Oxford: Basil Blackwell), 172-198.

Colombo, M. (2013). Moving forward (and beyond) the modularity debate: a network perspective. Philos. Sci. 80, 356-377. doi: 10.1086/ 670331

Frankenhuis, W. E., Panchanathan, K., and Barrett, H. C. (2013). Bridging developmental systems theory and evolutionary psychology using dynamic optimization. Dev. Sci. 16, 584-598. doi: $10.1111 /$ desc. 12053

Klein, C. (2012). Cognitive ontology and regionversus network-oriented analyses. Philos. Sci. 79, 952-960. doi: 10.1086/667843

Levy, A., and Bechtel, W. (2013). Abstraction and the organization of mechanisms. Philos. Sci. 80, 241-261. doi: 10.1086/670300

Piccinini, G. (2012). "Computationalism," in The Oxford Handbook of Philosophy of Cognitive Science, eds E. Margolis, R. Samuels, and S. P. Stich (New York, NY: Oxford University Press), 222-249.

Pinker, S. (1997). How the Mind Works. New York, NY: Norton.
Pinker, S. (2005). So how does the mind work? Mind Lang. 20, 1-24. doi: 10.1111/j.0268-1064.2005.00274.x

Sperber, D. (1996). Explaining culture: a naturalistic approach. Oxford: Blackwell.

Tooby, J., and Cosmides, L. (1990). The past explains the present: emotional adaptations and the structure of ancestral environments. Ethol. Sociobiol. 11, 375-424.

Tooby, J., and Cosmides, L. (1992). "The psychological foundations of culture," in The Adapted Mind: Evolutionary Psychology and the Generation of Culture, eds J. H. Barkow, L. Cosmides, and J. Tooby (New York, NY: Oxford University Press), 19-136.

Tooby, J., and Cosmides, L. (2005). "Conceptual foundations of evolutionary psychology," in The Handbook of Evolutionary Psychology, ed D. M. Buss (Hoboken, NJ: John Wiley \& Sons), 5-67.

Tooby, J., and Cosmides, L. (2008). "The evolutionary pscyhology of the emotions and their relationship to internal regulatory variables," in Handbook of Emotions, 3rd Edn., eds M. Lewis, J. M. HavilandJones, and L. F. Barrett (New York, NY: Guilford), 114-137.

Tooby, J., Cosmides, L., and Barrett, H. C. (2003). The second law of thermodynamics is the first law of psychology: evolutionary developmental psychology and the theory of tandem, coordinated inheritances: Comment on Lickliter and Honeycutt (2003). Psychol. Bull. 129, 858-865. doi: 10.1037/0033-2909.129.6.858

Wheeler, M., and Clark, A. (2008). Culture, embodiment and genes: unravelling the triple helix. Philos. Trans. R. Soc. B Biol. Sci. 363, 3563-3575. doi: $10.1098 /$ rstb.2008.0135

Conflict of Interest Statement: The author declares that the research was conducted in the absence of any commercial or financial relationships that could be construed as a potential conflict of interest.

Received: 20 September 2014; accepted: 05 November 2014; published online: 21 November 2014.

Citation: Klasios J (2014) Our computational nature: comment on Barrett et al. Front. Psychol. 5:1348. doi: 10.3389/fpsyg.2014.01348

This article was submitted to Evolutionary Psychology and Neuroscience, a section of the journal Frontiers in Psychology.

Copyright (c) 2014 Klasios. This is an open-access article distributed under the terms of the Creative Commons Attribution License (CC BY). The use, distribution or reproduction in other forums is permitted, provided the original author(s) or licensor are credited and that the original publication in this journal is cited, in accordance with accepted academic practice. No use, distribution or reproduction is permitted which does not comply with these terms. 